\title{
Role of the Neural Retina in Newt (Notophthalmus viridescens) Lens Regeneration In Vitro
}

\author{
THOMAS G. CONNELLY, M. SEAN GREEN, WALTER M. SAHIJDAK, \\ AND ROBERT M. LOYD \\ Department of A natomy and Cell Biology, The University of Michigan, \\ Ann Arbor, Michigan 48109-0010 (T.G.C., M.S.G., W.M.S); Carl Zeiss Inc., \\ Thornwood, New York 10594 (R.M.L.)
}

\begin{abstract}
Removal of the lens from the eye of an adult newt (Notophthalmus viridescens) is followed by regeneration of a new lens from the dorsal iris epithelial cells at the pupillary margin. This process is dependent upon the neural retina for its normal completion in vivo and in vitro. To examine the relationship between the retina and lens regeneration, we have conducted experiments that delimit the time period during which the retinal presence is critical (in vivo) and have investigated the influence of extracts of the retina on the progress of regeneration (in vitro).

In vivo, removal of the retina at day 11 seriously retards further progression of regeneration while removal of the retina at day 15 does not retard regeneration significantly. This defines a "critical period" in regeneration of the lens during which the retina is required.

Explantation of regenerates 11 or 12 days after lentectomy to organ culture medium enriched with either crude retinal homogenate or extracts prepared from chick or bovine retinas according to Courty et al. ('85, Biochimie, 67:265269) reveals that the progress of regeneration can be supported in culture by the crude extract. This is the first demonstration of complete iris-lens transformation in culture in the presence of retinal extract.

It is possible that the retina acts indirectly by promoting passage of the iris epithelial cells through the critical number of mitoses required before redifferentiation into lens cells can occur (as proposed by Yamada, '77, Monogr. Dev. Biol., 13:126). It is also possible that the retina acts by directly instructing the iris cells to redifferentiate. Our experiments provide some indirect support for the first possibility but do not distinguish between them at this time.
\end{abstract}

Removal of the lens from the eye of an adult newt (Notophthalmus viridescens) initiates the production of a new lens from the pigmented dorsal iris epithelial cells (Yamada, '67, '77; Yamada and McDevitt, '84). Lentectomy stimulates cells at the mid-dorsal pupillary margin to reenter the cell cycle and to depigment. Following 5 to 6 cell divisions, progeny of some of these depigmented cells redifferentiate as lens fiber cells containing lens-specific crystallin proteins (pathway of conversion; Yamada and McDevitt, '84). Others undergo repigmentation, remaining as iris epithelial cells (pathway of retrieval; Yamada and $\mathrm{McDevitt,} \mathrm{'84).} \mathrm{In} \mathrm{vivo}$ this process depends upon the neural retina for its normal completion (Reyer, '66, '71;
Stone, '58; Stone and Steinitz, '53; and see below). The process of lens regeneration will occur in vitro if neural retina is provided (Yamada et al., '73) or if irises are cultured in contact with pituitary glands (Connelly et al., '73; Connelly, '77).

Results of previous studies (Zalokar, '44; Eguchi, '67; Eisenberg-Zalik and Scott, '69; Reese et al., '69; Reyer, '71; Reese, '73; Connelly, '77; Williams and McGlinn, '79) suggested to us that the early events of regeneration (initiation, depigmentation, initiation of DNA synthesis) could occur in the absence of the retina or other stimuli. Further, these experiments suggested that there might be a "critical period" later in regeneration during which the retina (or other stim- 
uli in vitro) must be present for normal regeneration to occur. Consequently, we undertook, experiments aimed at determining if such a critical period did exist. These experiments were followed by others designed to determine the nature of the retinal effect during this critical period. Our working hypothesis, originally formulated by Yamada ('82), was that the retinal "factor" acts as a facilitator of regeneration. Facilitation would be accomplished by helping depigmented cells in the pathway of conversion to pass through the requisite number of cell cycles prior to their conversion to lens cells. This hypothesis led us to perform an experiment originally alluded to by Yamada ('84), testing the effects of mitogenic eye-derived growth factor(s) ad defined by Courtois (Arruti and Courtois, '78; Barritault et al., '81; Barritault et al., '82) on iris-lens transformation in vitro in irido-corneal complexes explanted during the critical period after lens removal.

\section{MATERIALS AND METHODS General methods}

Newts (Notophthalmus viridescens) obtained from Bill Lee's Newt Farms (Oak Ridge, TN) and maintained at $21^{\circ} \mathrm{C}$ were used in all experiments. Animals were anesthetized in a 1:1,000 aqueous solution of ethylm-aminobenzoate methane sulfonate (EAMS; Sigma, St. Louis, MO) prior to any surgery. For simple lens removal, animals were anesthetized, small paper plugs were inserted into their mouths to put gentle pressure on their eyeballs from the oral side, and a single nasotemporal incision at the equator of the eye was made through the cornea with a \#11 scalpel blade. By exerting gentle pressure on the eye with watchmakers forceps, the experimenter can express the lens from the optic cavity. When this is done correctly, no damage to the iris occurs, no bleeding is induced, and animals can be returned immediately to their tanks for recovery.

Removal of the neural retina was accomplished by making a small incision at the corneo-scleral junction in the mid-ventral region of the eye. A small bore pipette (flame pulled Pasteur pipette) was then used to flush the optic cavity with $80 \%$ phosphate buffered saline $\left(\mathrm{PBS}_{80}\right)$ to free the neural retina. The dislodged retina was then removed from the optic cavity by gentle suction with a slightly larger bore pipette. Efficacy of the operative technique was confirmed by histological examination of several eyes fixed immediately after surgery. No adherent retina was found after we had performed several test opera tions.

For organ culture experiments, animals were soaked for 30 minutes in a weak (5-10 $\mathrm{mg} / \mathrm{L}$ ) solution of $\mathrm{KMnO}_{4}$ (Rounds, '73; Connelly, '77), anesthetized as above including the placement of mouth plugs, and then their heads and eyes were rinsed for about 30 seconds in a steady stream of $70 \%$ ETOH followed by a brief rinse with sterile distilled water. All subsequent operations were performed in a laminar flow hood.

A small incision was made at the corneoscleral junction with a \#11 scalpel blade. By the use of small iridectomy scissors (Fine Science Tools), this incision was extended around the circumference of the eye at the corneo-scleral junction and the entire iridocorneal complex was then lifted off the eye. The irido-corneal complexes (ICCs) were rinsed in complete culture medium (containing $50 \mu \mathrm{g} / \mathrm{ml}$ of Gentamycin (see below) and then explanted to an organ culture environment as described previously (Connelly, '77). Usually 3 to 5 ICCs were fixed at the time of explantation to determine the stage of regeneration attained by the group at the initiation of the experiment.

In cases where extracts were added to the culture medium, aliquots of the extracts were sterilized by filtration and the protein concentration of each was then determined by the Lowry method.

Statistical analysis of data was carried out with the Mann-Whitney U test via the University of Michigan's MIDAS statistical package written and supported by the Statistical Research Laboratory.

\section{Organ culture methods}

Basic methods of culturing newt ICCs used in this laboratory for several years were also used here. Culture medium consists of $50 \%$ Leibovitz L-15 medium (GIBCO, Grand Island), $40 \%$ sterile glass distilled water, $10 \%$ fetal calf serum (HyClone), $50 \mu \mathrm{g} / \mathrm{ml}$ gentamicin ), and $5 \mathrm{mM}$ HEPES (Sigma, St. Louis, MO). ICCs are explanted onto filter paper supports (Gelman Metricel GN-6, Gelman Sciences, Ann Arbor, MI). The filter papers are, in turn, supported by a triangular stainless steel mesh that dips into the central well of an organ culture dish (Falcon Plastics). Culture medium is placed in the central well to a level that just wets the stainless steel 
grid, wetting the filter paper and covering the ICCs with a very thin layer of moisture. Cultures are maintained at $25^{\circ} \mathrm{C}$ in an incubator and in humid chambers.

\section{Histological methods}

Cultures were evaluated histologically. Filter papers with adherent ICCs were fixed in Bouin's fluid overnight. They were dehy. drated through a graded series of ethanols to $100 \%$, cleared in methyl salicylate, infiltrated and embedded in paraffin. Serial 10 . $\mu \mathrm{m}$ sections were prepared and mounted on sub-bed slides. After deparaffinization, sections were stained with hematoxylin and eosin and regenerates were evaluated for stage attained to Yamada's ('67) modification of Sato's staging system.

\section{Measurement of thymidine incorporation by irises}

Thymidine incorporation by irises in culture was determined by the use of slight modification of the methods of Jauker and Yamada ('73). Groups of ten irises each were labeled with $10 \mu \mathrm{Ci} / \mathrm{ml}$ of ${ }^{3} \mathrm{H}$-thymidine for 4 hours in vitro. At the end of the labeling period, irises were rinsed in culture medium free of label and then homogenized in $1.0 \mathrm{ml}$ of extracting medium. Extracting medium consisted of $100 \mathrm{ml} .01 \mathrm{M}$ Tris, $.03 \mathrm{~g} \mathrm{MgCl}_{2}$, $.07 \mathrm{~g} \mathrm{KCl}, .82 \mathrm{~g} \mathrm{NaCl}$, and $1 \mathrm{~g}$ sodium dodecyl sulfate. The homogenizer was rinsed with an additional milliliter of extracting medium. The homogenate was spun briefly to remove debris and $.2 \mathrm{ml}$ of the supernatant was placed on a glass fiber filter. The filters were air-dried, washed in ice-cold $10 \%$ trichloroacetic acid (TCA) for 30 minutes, then two times in ice-cold 5\% TCA for an additional 15 mintues for each wash. The filters were then run up through a graded series of alcohols to $100 \%$, rinsed briefly in acetone and dried. Filters were then placed in scintillation vials, $5.0 \mathrm{ml}$ of Aquasol (New England Nuclear, Boston, MA) scintillation fluid was added to the vials, and the amount of radioactivity incorporated was determined with a Beckman LS-9000 liquid scintillation spectrometer. Results were expressed as DPM/100 irises (Jauker and Yamada, '73).

\section{Preparation of extracts}

Extracts of neural retinas from 11-15-dayold chicks (Dave's Poultry Farms, Ann Arbor, MI) and from adult bovine eyes (Monarch Packing, Detroit, MI) were prepared.
Preparation of extracts was the same for both sources. All steps were carried out on ice or at $4^{\circ} \mathrm{C}$ unless otherwise specified. Eyes were enucleated and split in half with scissors or a \#11 scalpel blade. The lens and vitreous were removed and the neural retina was removed by gentle teasing with blunt forceps. Retinas were placed immediately into icecold PBS until homogenized. Retinas were homogenized in a Dounce homogenizer in equal volumes of PBS. The homogenate was then centrifuged at $20,000 \mathrm{~g}$ for 20 minutes in a Beckman A-19 rotor to remove cellular debris and any adherent pigment removed at the dissection. The supernatant was then spun at $100,000 \mathrm{~g}$ for 2 hours in a Beckman Ti-42 rotor. The supernatant from this spin is called the crude homogenate $(\mathrm{CH})$.

To prepare a crude extract (CE) of the homogenate, ammonium sulfate was added to the supernatant of the $100,000 \mathrm{~g}$ spin to a final concentration of $0.8 \mathrm{M}$. This solution was centrifuged at $20,000 \mathrm{~g}$ for 20 minutes and any pellet found was discarded. The supernatant was then brought to a final concentration of $2.5 \mathrm{M}$ ammonium sulfate. The flocculent material precipitated at this step was pelleted by a 20 -minute centrifugation at $20,000 \mathrm{~g}$. The supernatant was discarded and the pellet dissolved in PBS. This solution was then dialyzed for 1 to 2 days against 4 to 6 liters of PBS or saline at $4^{\circ} \mathrm{C}$.

\section{Cibacron blue chromatography}

Crude extract was fractionated on a column of cibacron blue gel (Biorad Labs) after the method of Barritault et al. ('82). A maximum of $29 \mathrm{mg}$ of $\mathrm{CE} / \mathrm{mg}$ of the gel was applied to a column equilibrated with PBS. Flow rate during sample application was 15 $\mathrm{cm} / \mathrm{hr}$. The column was washed with PBS and eluted with $0.65 \mathrm{M} \mathrm{NaCl}$, and then with $2.15 \mathrm{M} \mathrm{NaCl}$ (presumably containing Courtois' EDGF I and II), and finally with $2 \mathrm{M}$ $\mathrm{NaCl} / 2 \mathrm{M}$ urea (to regenerate the column) at a flow rate of $30 \mathrm{~cm} / \mathrm{hr}$. Protein concentration was measured by the method of Lowry with bovine serum albumin as a standard. Samples were stored at $-20^{\circ} \mathrm{C}$ in elution buffer.

\section{Mitogenic assay}

In order to be sure that the extract(s) we were testing for lens regeneration enhancement were active according to the definition of eye-derived growth factors of Courtois, a modification of the procedures of Barritault 
et al. ('82) and Plouet et al. ('84) for such an assay was followed. Bovine corneal endothelial (BCE) cells, graciously provided by Drs. Donald MacCallum and John Lillie (Department of Anatomy and Cell Biology, The University of Michigan), were used as test cells for mitogenicity of the various fractions obtained from chick and bovine eyes. Serially subcultured BCE cells (2-5 passages in medium containing no added growth factors) were seeded at a density of $1 \times 10^{3}$ cells per well into 96-well plates (Falcon). Culture medium consisted of either MEM or M-199 (Gibco) supplemented with $2 \mathrm{mM} \mathrm{L-gluta-}$ mine, $10 \%$ FCS, $50 \mu \mathrm{g} / \mathrm{ml}$ Gentamicin, and $10 \mathrm{mM}$ HEPES. After 72 hours, fractions to be tested (along with appropriate buffer controls) were added to individual test wells in volumes of 2-15 $\mu \mathrm{l}$. After a 24-hour incubation period the process was repeated. Twentyfour hours later, cells were labeled with ${ }^{3} \mathrm{H}$ thymidine $(0.1 \mathrm{MC} /$ well $)$ for 4 hours. The cell monolayers were then washed three times with PBS and lysed overnight in $0.5 \mathrm{M} \mathrm{NaOH}$ in $1 \% \mathrm{SDS}$. The lysate was then neutralized with $1 \mathrm{M} \mathrm{HCl}$ and counted in $4 \mathrm{ml}$ of ACS scintillation cocktail (Amersham) in a Beckman LS-9000 spectrometer (Lillie et al., '82).

\section{Immunofluorescence methods}

To confirm the presence of lens crystallins in regenerates obtained in culture, some regenerates were examined by immunofluorescence methods. Regenerates were fixed in cold $95 \%$ ethanol, dehydrated and cleared in the cold, embedded and then sectioned histologically at $5 \mu \mathrm{m}$ thickness. Sections (mounted on sub-bed slides) containing the most advanced regenerates from treated and control groups were then deparaffinized. Sections were rinsed in PBS and then covered with 50 $\mu l$ of anti-newt gamma crystallin antibody (kindly provided by Dr. David S. McDevitt of the University of Pennsylvania). After 1 hour, sections were rinsed in PBS and fluorescein-labeled goat anti-rabbit secondary antibody was applied. One hour later the sections were rinsed and examined with epifluorescence microscopy. Negative controls consisting of sections incubated only with second antibody only were also included.

\section{RESULTS \\ Influence of retina removal on lens regeneration in vivo}

Newts were bilaterally lentectomized. On days $0,3,6,9,11$, and 15 after lentectomy, groups of newts were also subjected to surgical removal of the neural retina. Eighteen days after lentectomy, eyes were fixed and examined histologically to determine the extent of lens regeneration. The results of this experiment are shown in Table 1. Simultaneous lentectomy and retina removal results in a retardation of regeneration, but some advanced regenerates do form by 18 days. We interpret the production of some regenerates in the day 0 group to reflect the effects of regenerated retina produced during the 18 day extent of the experiment (as evidenced by the presence of bilayered retinal regenerates visible histologically). These results confirm those of Stone and Steinitz ('53), Stone ('58), and Reyer ('66). They expand upon them by showing that removal of the retina as late as 11 days after lentectomy has a marked effect on the progress of regeneration during the next 7 days. In fact, the regenerates produced by most eyes in these groups progress only to about stage $\mathrm{V}$ of regeneration. Just 4 days later, at $\mathbf{1 5}$ days, removal of the retina has little or no effect on the progress of regeneration (at least by morphological criteria). We interpreted these results as demonstrating the existence of a "critical period" (between day 11 and day 15) during which the neural retina is required for the further normal progress of regeneration.

\section{Influence of $\mathrm{CH}$ and $\mathrm{CE}$ on progress of regeneration in culture during the critical period}

In order to determine if extracts of retina would promote further regeneration of lens regenerates explanted during the critical period, irido-corneal complexes (ICCs) were explanted on day 11 or 12 after lens removal. Results from both explantation days are essentially identical. Organ culture medium was enriched with $\mathrm{CH}, \mathrm{CE}$, or with the fraction obtained by passing CE over a Cibacron Blue column and eluting with $2.15 \mathrm{M}$ salt. The results are shown in Tables $2-5$. Tables 2 and 3 show the results obtained with extracts prepared from chick retinas while results in Tables 4 and 5 were obtained by enriching medium with extracts from bovine retinas. While chick $\mathrm{CH}$ appears to have no effect on regeneration, bovine $\mathrm{CH}$ appears to have a slight effect on the progress of regeneration by regenerates in organ culture during a 7-10-day culture period. Crude extract appears to cause the formation of a higher percentage of advanced regenerates and also 
TABLE 1. Influence of sequential retina removal on the progress of lens regeneration in vivo ${ }^{\mathrm{a}}$

\begin{tabular}{lll}
$\begin{array}{l}\text { Day of retinal } \\
\text { removal }\end{array}$ & $\begin{array}{c}\text { Depigmentation } \\
\text { only (\%) } \\
\text { (stages II-V) }\end{array}$ & $\begin{array}{c}\text { Fiber } \\
\text { differentiation (\%) } \\
\text { (stages VI-XI) }\end{array}$ \\
\hline 0 & $50(4 / 8)$ & $50(4 / 8)$ \\
3 & $84(5 / 6)$ & $16(1 / 6)$ \\
6 & $100(6 / 6)$ & \\
9 & $100(3 / 3)$ & $16(1 / 6)$ \\
11 & $84(5 / 6)$ & $78(7 / 9)$ \\
15 & $22(2 / 9)$ & $100(8 / 8)$ \\
Shamop & & \\
controls & & \\
\hline
\end{tabular}

${ }^{a}$ Regenerates in the advanced group show clear evidence of completion of the transformation from iris to lens. We interpret the presence of some advanced regenerates in the day 0 group to reflect the effects of retina regenerated during the course of the experiment.

TABLE 2. Influence of chick retina crude homogenate $(\mathrm{CH})$ on progress of lens regeneration in culture

\begin{tabular}{lclc}
$\begin{array}{l}\text { Treatment } \\
(\mu \mathrm{g} / \mathrm{ml})\end{array}$ & $\mathrm{N}$ & $\begin{array}{c}\text { Depigmentation } \\
\text { only }(\%)\end{array}$ & $\begin{array}{c}\text { Fiber } \\
\text { differentiation } \\
(\%)\end{array}$ \\
\hline Control & 9 & $78(7 / 9)$ & $22(2 / 9)$ \\
100 & 6 & $100(6 / 6)$ & \\
250 & 9 & $100(9 / 9)$ & \\
\hline
\end{tabular}

TABLE 3. Influence of chick retina crude extract (CE) on progress of lens regeneration in culture ${ }^{\mathbf{a}}$

\begin{tabular}{lclc}
$\begin{array}{l}\text { Treatment } \\
(\mu \mathrm{g} / \mathrm{ml})\end{array}$ & $\mathrm{N}$ & $\begin{array}{c}\text { Depigmentation } \\
\text { only }(\%)\end{array}$ & $\begin{array}{c}\text { Fiber } \\
\text { differentiation } \\
(\%)\end{array}$ \\
\hline Control & 16 & $81(13 / 16)$ & $19(3 / 16)$ \\
25 & 13 & $85(11 / 13)$ & $15(2 / 13)$ \\
250 & 17 & $65(11 / 17)$ & $35(6 / 17)$ \\
500 & 13 & $39(5 / 13)$ & $61(8 / 13)$ \\
\hline
\end{tabular}

${ }^{a}$ The differences between controls and the 250 and $500 \mu \mathrm{g} / \mathrm{ml}$ groups are statistically significant $(p<0.05)$ by the Mann. Whitney U test.

produces generally more advanced stages beyond stage VI (personal observation). The effect of CE appears to be dose dependent. Clearly, this factor is active in enhancing production of advanced regenerates in the bioassay. The bovine extract is especially active in this respect. Examples of the types of regenerates obtained with and without treatment are presented in Figure 1.

We have examined the regenerates obtained in such experiments using immunofluorescence methods to detect the presence of gamma crystallins. Regenerates that appear to be advanced morphologically also bind anti-gamma antibodies as shown by indirect immunofluorescence while those categorized on a morphological basis as early stages (pre-stage VI) do not. Thus, regenerates that we consider advanced on morphological criteria also satisfy the criteria for transdifferentiation as indicated by production of lens-specific proteins.

We have tested $\mathrm{CH}, \mathrm{CE}$, and the $2.15 \mathrm{M}$ salt fraction from the Cibacron Blue column in the $\mathrm{BCE}$ mitogenesis assay and find that all are active in promoting thymidine incorporation by the test cells. Stimulation by these preparations can range from 1.6 times control values (for $\mathrm{CH}$ ) to more than 5 times greater than controls (for CE). We interpret these results and those above as indicating that the precipitation procedure concentrates the activity we are seeking. These results confirm those of Courty et al. ('85). Although we do not have complete dose-response data, the specific activity of our preparations appears similar to that described by Courtois and colleagues.

\section{Influence of $C E$ on thymidine incorporation by dorsal iris pieces in culture}

Our primary purpose in this paper was not to examine the mechanism by which $\mathrm{CE}$ might enhance regeneration. It was deemed important to determine if the material we were testing would not only enhance thymidine incorporation by BCE cells, but would also stimulate thymidine incorporation by our actual test cells. To this end, newts were bilaterally lentectomized. On day 12 after lentectomy, just the lens forming area from the dorsal iris (DI pieces, Connelly et al. '73) were explanted to culture medium. For these experiments, iris pieces were not cultured in the organ culture environment described above, but they were simply cultured in 1.0 $\mathrm{ml}$ of medium in $35-\mathrm{mm}$ Falcon culture dishes. The dishes were kept in a humid environment to prevent evaporation (Jauker and Yamada, '73). Fifteen groups of ten irises each were explanted. Six groups of ten irises each were explanted to medium containing 100 micrograms $/ \mathrm{ml}$ of chick retina CE. Nine groups of ten irises each were explanted into standard culture medium. Three of these nine groups were placed immediately into standard culture medium containing $10 \mu \mathrm{Ci} /$ $\mathrm{ml}$ of labeled thymidine to measure incorporation levels at the onset of the experiment. Four hours later, these cultures were pro- 
$T A B L E 4$. Influence of bovine retina crude homogenate (CH) and crude extract (CE) on progress of lens regeneration in culture ${ }^{\text {a }}$

\begin{tabular}{lrlc}
$\begin{array}{l}\text { Treatment } \\
(\mu \mathrm{g} / \mathrm{ml})\end{array}$ & $\mathrm{N}$ & $\begin{array}{c}\text { Depigmentation } \\
\text { only }(\%)\end{array}$ & $\begin{array}{c}\text { Fiber } \\
\text { differentiation } \\
(\%)\end{array}$ \\
\hline Control & 11 & $100(11 / 11)$ & \\
CH 250 & 10 & $60(6 / 10)$ & $40(4 / 10)$ \\
CE 250 & 13 & $46(6 / 13)$ & $54(7 / 13)$ \\
CE 500 & 11 & $27(3 / 11)$ & $73(8 / 11)$ \\
\hline
\end{tabular}

'The differences between controls and the 250 and $500 \mu \mathrm{g} / \mathrm{ml}$ groups are statistically significant $(p<0.01)$ by the MannWhitney U test.

TABLE 5. Influence of the 2.15 $\mathrm{M} \mathrm{NaCl}$ fraction from a cibacron blue column on progress of regeneration in vitro

Fiber

\begin{tabular}{lrlc}
$\begin{array}{l}\text { Treatment } \\
(\mu \mathrm{g} / \mathrm{ml})\end{array}$ & $\mathrm{N}$ & $\begin{array}{c}\text { Depigmentation } \\
\text { only }(\%)\end{array}$ & $\begin{array}{c}\text { differentiation } \\
(\%)\end{array}$ \\
\hline Control & 10 & $100(10 / 10)$ & 0 \\
CE 500 & 7 & $14(1 / 7)$ & $86(6 / 7)$ \\
$2.15 \mathrm{M} 25$ & 9 & $13(1 / 9)$ & $87(8 / 9)$ \\
\hline
\end{tabular}

cessed for liquid scintillation counting as described in methods.

Two and four days later (14 and 16 days total regeneration time), three groups of ten irises each of the treated and control irises were labeled with thymidine and the incorporation of thymidine determined as above. The results of this experiment are shown in Table 6. The data show that treatment of the cultured iris pieces with $\mathrm{CE}$ increases thymidine incorporation into the acid insoluble fraction by about $20 \%$ over untreated cultures at both time periods examined.

\section{DISCUSSION}

Though the importance of neural retina for normal lens regeneration has been known for a long time, few experiments have been performed to test directly the effects of neural retina on regeneration of the lens. Yamada ('82) has stated that with the advent of more clearly defined culture conditions it should now be possible to design experiments that probe more deeply into the relationship between iris and retina during the regeneration process. To our knowledge only two other investigators have attempted experiments similar to those described in this paper. The $\mathrm{PhD}$ thesis research of Borst ('84) was the first to address the influence of EDGF on regeneration in vivo and was carried out by injecting small volumes of crude EDGF di- rectly into the eye. Her results were extremely interesting because she reported the formation of second lenses forming from the ventral iris. Her case numbers were very small, but her results were nonetheless stunning. Unpublished experiments have been performed by Courtois and Cuny (personal communication) using in vitro methods with results that appear to be relatively similar to those we report. They have not, however, utilized the critical period approach to limit their analysis to a more clearly defined portion of the regeneration process.

The results of experiments described above demonstrate the existence of a critical period in lens regeneration during which the presence of the neural retina is required. These results consolidate and confirm what is implied from indirect evidence in the literature. Definition of a critical period in regeneration has allowed us to devise a relatively shortterm in vitro bioassay for analysis of the retinal influence on regeneration. Although not an absolute necessity for such analysis, the short time in culture (7-10 days) greatly reduces the amount of material required for each assay. More importantly, delineation of the critical period allows us to concentrate on the events taking place during the phases of regeneration immediately surrounding the transformation of iris cells into lens cells, helping to identify those events most likely to be required for regeneration and making it easier to identify alternatives for a mechanism of action of the retinal factor.

Our data represent the first demonstration of a response of lens regenerates to retinal extracts in culture. Although in earlier experiments we were unable to duplicate the effects of the pituitary gland by adding hormones to the culture medium (Connelly, '77), we can now produce enhancement of regeneration of the lens by adding retinal extract to the culture medium. Our primary purpose was to determine if substances that were presumably mitogenic would also enhance the progression of lens regeneration (as proposed by Yamada, '84) in vitro during the critical period (when retina is required by the regenerate). But, one must keep in mind that our primary goal was to study the effects of substances that promote regeneration, not simply to search for mitogens for newt iris epithelial cells. Test extracts failing to produce advancement of regeneration, as did hormones (Connelly, '77), would be of little interest in terms of their effects on incorpo- 

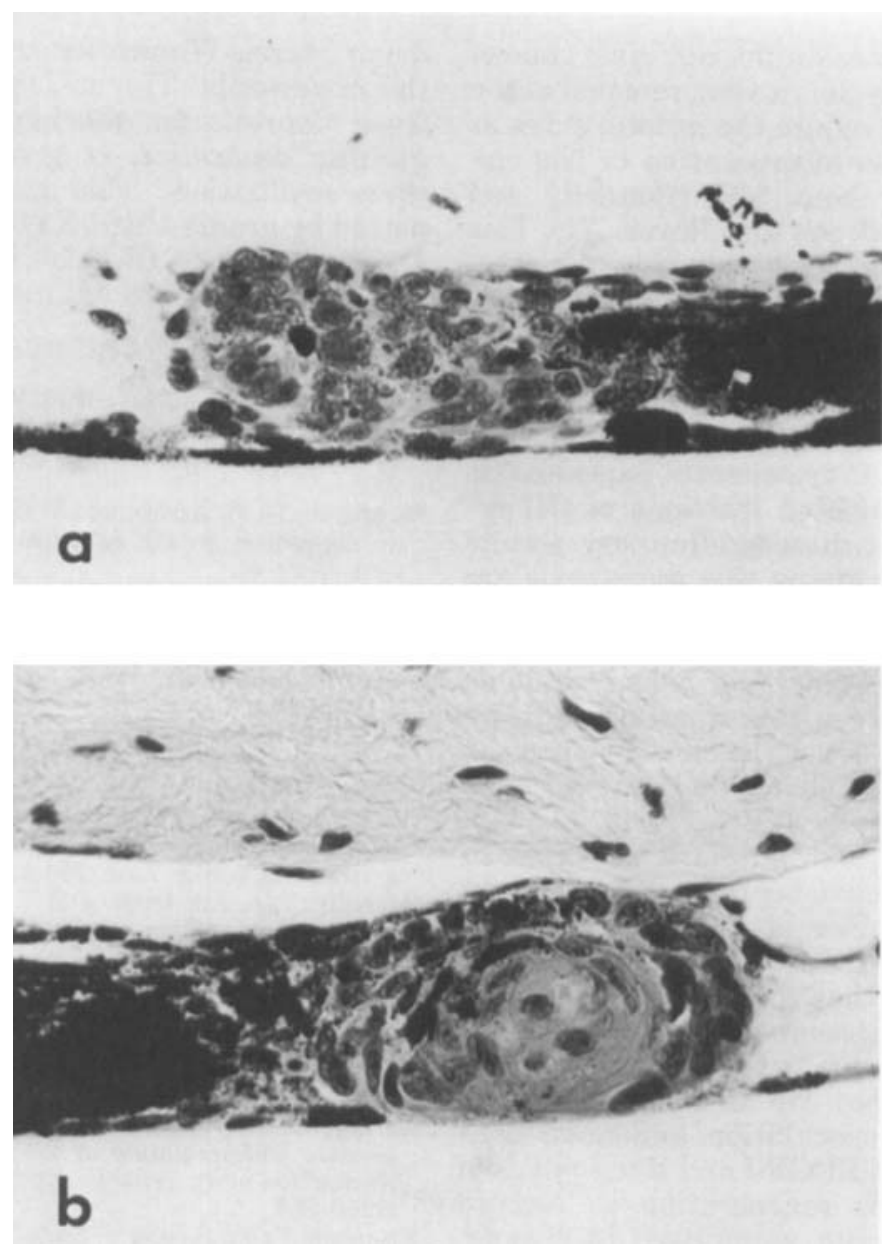

Fig. 1. Photomicrographs of lens regenerates typical of those obtained in vitro in control (a) or bovine $\mathrm{CE}$ treated (b) cultures. Both were explanted on day 11 postlentectomy and cultured for an additional 10 days in standard medium (a) or in medium enriched with 500

ration of thymidine by regenerates during the culture period.

Our experiments show that progression of regeneration is significantly enhanced by $\mathrm{CE}$ and that $\mathrm{CE}$ enhances incorporation of thymidine by regenerates explanted during the critical period. We have also performed preliminary experiments looking at the effects of neural retina on thymidine incorporation and cell cycling by regenerates explanted during the critical period. These preliminary results (Connelly, Loyd, and Green, unpublished) appear to show that the retina seems to enhance the number of cells cycling through mitosis in culture but does not seem $\mu \mathrm{g} / \mathrm{ml}$ of bovine CE. The regenerate in a is equivalent to Sato stage IV while that in $b$ is equivalent to Sato stage IX. Note the core of primary lens fiber cells in the regenerate in $b$.

TABLE 6. Influence of chick retina (CE) on thymidine incorporation by dorsal iris pieces explanted on day 12 after lentectomy

Time in culture

\begin{tabular}{lll} 
(days) & Treatment & DPM/10 irises \\
\hline 0 & Untreated $^{\mathrm{a}}$ & $6,293 \pm 416$ \\
2 & Untreated $^{b}$ & 6,291 \\
2 & $\mathrm{CE}$ & $8,265 \pm 1,083$ \\
4 & Untreated & $8,136 \pm 1,152$ \\
4 & $\mathrm{CE}$ & $9,834 \pm 1,549$
\end{tabular}

aThis method of expressing results has been used by Jauker and Yamada ('73). Values are means \pm standard deviations.

bonly two groups of ten irises each were available for labeling at this postexplantation time period. 
to have an influence on the cell cycle time of the cells that do cycle. In vivo, removal of the retina appears to reduce the mitotic index as well as thymidine incorporation of iris epithelial cells by about 50\% (Connelly and Loyd, unpublished; see also Reyer, '71). This effect is similar to that obtained by denervation of an amphibian limb regeneration blastema (Tassava et al., '85). These preliminary results are provocative but do not provide direct evidence that the primary event influenced by the retina or by retinal extract is cell proliferation. Consequently, experiments utilizing more purified fractions of $\mathrm{CE}$ designed to confirm these preliminary results and to further examine this hypothesis are now under way in this laboratory.

One might ask if the enhancement activity is unique to the retina. Our experiments do not directly address this question, but we suspect that this is not the case. In vitro the pituitary gland is able to enhance lens regeneration dramatically (Connelly et al., '73; Connelly, '77). The similarities between EDGF and FGF have been described (Courty et al., '85; Schreiber et al., '85). Since the pituitary is a rich source of FGF it is tempting to speculate that the reason it produces such marked enhancement of lens regeneration in culture is due to release of FGF or an FGF-like substance. We have no evidence to support such a speculation and have data that suggest that EDGF-I and II are not able to stimulate lens regeneration in culture (Connelly and Green, submitted). In vivo deplantation of the iris into a limb regeneration blastema results in formation of advanced lens regenerates in the absence of the neural retina (Reyer et al., '73). Thus, substances from a variety of sources may enhance regeneration. Only after we have delineated the nature of the retinal activity will we be able to determine the distribution of similar activities through various tissues. If the hypothesis that the critical event is mitotic stimulation proves true, it would not be surprising that a number of other mitogenic agents could substitute for the retinal activity.

\section{ACKNOWLEDGMENTS}

Thanks are due to Drs. David C. Beebe, David S. McDevitt, Randall W. Reyer, and Tuneo Yamada for consulting during the design of some of the experiments reported in this paper and for their critical evaluation of the manuscript. Thanks are also due to Ms.
Joyce Morris-Wiman for critical reading of the manuscript. The authors also thank Dr. Yves Courtois for sharing information regarding separation of growth factors and their evaluation. This research was supported by grants 1 R01-EY05419 (T.G.C.) and 1 F32-EY05302 (R.M.L) from the Public Health Service-National Institutes of Health.

\section{LITERATURE CITED}

Arruti, C., and Y. Courtois (1978) Morphological changes and growth stimulation of bovine epithelial lens cells by a retinal extract in vitro. Exp. Cell Res., 117:283291.

Barritault, D., C. Arruti, and Y. Courtois (1981) Is there an ubiquitous growth factor in the eye? Differentiation, 18:29-41.

Barritault, D., J. Plouet, J. Courty, and Y. Courtois (1982) Purification, characterization and biological properties of the eye derived growth factor from retina. Analogies with brain derived growth factor. J. Neurosci. Res., $8: 477-490$.

Borst, D.E. (1984) Eye lens regeneration and the crystallins in the adult newt, Notophthlamus viridescens. PhD thesis, University of Pennsylvania, Philadelphia.

Connelly, T.G. (1977) Pituitary enhancement of Wolffian lens regeneration in vitro: Spatial and temporal requirements. J. Exp. Zool., 200:359-364.

Connelly, T.G., J.R. Ortiz, and T. Yamada (1973) Influence of the pituitary on Wolffian lens regeneration, Dev. Biol., 31:301-315.

Courty, J, C. Loret, M. Moenner, B. Chevallier, O. Lagente, Y. Courtois and D. Barritault (1985) Bovine retina contains three growth factor activities with different affinity to heparin: Eye derived growth factor, I, II, III. Biochimie, 67:265-269.

Eguchi, G. (1967) In vitro analysis of Wolffian lens regeneration. Differentiation of the developing lens rudiment of the newt, Triturus pyrrhogaster. Embryologia, 9:246-266.

Eisenberg-Zalik, S., and V. Scott (1969) In vitro development of the regenerating lens. Dev. Biol., 19:368-383.

Jauker, F., and T. Yamada (1973) Progressive alteration in the pattern of nucleic acid metabolism in the newt iris in cultivation. J. Exp. Zool., 183:145-157.

Lillie, J.H., D.K. MacCallum, and A. Jepsen (1982) The behavior of subcultivated stratified squamous epithelial cells on reconstituted extracellular matrices: Initial interactions. Eur. J. Cell Biol., 29:50-60.

Plouet, J., J. Courty, M. Olivie, Y. Courtois, and D. Barritault (1984) Highly reliable and sensitive assay for the purification of cellular growth factors. Cell. Molec. Biol., 30:105-110.

Reese, D.H. (1973) In vitro initiation in the newt iris of some early molecular events of lens regeneration. Exp. Eye Res., 17:435-444.

Reese, D.H., E. Puccia, and T. Yamada (1969) Activation of ribosomal RNA synthesis in initiation of Wolffian lens regeneration. J. Exp. Zool., 17:259-268.

Reyer, R.W. (1966) The influence of neural retina and lens on lens regeneration from dorsal iris implants in Triturus viridescens larvae. Dev. Biol., 14:214-225.

Reyer, R.W. (1971) DNA synthesis and the incorporation of labeled iris cells into the lens during lens regeneration in adult newts. Dev. Biol., 24:535-558.

Reyer, R.W., R.A. Woolfitt, and L.T. Withersty (1973) Stimulation of lens regeneration from newt dorsal iris when implanted into the blastema of the regenerating limb. Dev. Biol., 32:258-281. 
Rounds, D.E. (1973) Adult amphibian tissues and leukocytes. In: Tissue Culture: Methods and Applications. P.F. Kruse and M.K. Patterson, eds. Academic Press, New York, pp. 129-133.

Schreiber, S.B., J. Kenney, J. Kowalski, K.A. Thomas, G. Gimenz-Gallo, M. Rios-Candelore, J. DiSalvo, D. Barritault, J. Courty, Y. Courtois, M. Moenner, C. Loret, W.H. Burgess, T. Mehlam, R. Friesel, W. Johnson, and T. Maciag (1985) A unique family of endothelial cell polypeptide mitogens: The antigenic and receptor cross-reactivity of bovine endothelial cell growth factor, brain-derived acidic fibroblast growth factor, and eye derived growth factor-II. J. Cell Biol., 101:1623-1626.

Stone, L.S. (1958) Inhibition of lens regeneration in newt eyes by isolating the dorsal iris from the neural retina. Anat. Rec., 131:151-172.

Stone, L.S., and H. Steinitz (1953) The regeneration of lenses in eyes with intact and regenerating retina in adult newt, Triturus v. viridescens. J. Exp. Zool., 124:435-468.

Tassava, R.A., D.L. Laux, and D.P. Treece (1985) The effects of partial and complete denervation on adult newt forelimb blastema cell cycle parameters. Differ- entiation, 29:212-126.

Williams, L.A., and M. McGlinn (1979) Stimulation of lens regeneration in vitro, by growth factors and spinal ganglia. Am. Zool., 19:923 (Abstract).

Yamada, T. (1967) Cellular and subcellular events in Wolffian lens regeneration, Curr. Top. Dev. Biol., 2:247-283.

Yamada, T. (1977) Control mechanisms in cell type conversion in newt lens regeneration. Monogr. Dev. Biol., 13:126.

Yamada, T. (1982) Transdifferentiation of lens cells and its regulation. In: Cell Biology of the Eye. D.S. McDevitt, ed. Academic Press, New York pp. 193-242.

Yamada, T. (1984) Developmental control of cell differentiation. Zool. Sci., 1:333-348.

Yamada, T., and D.S. McDevitt (1984) Conversion of iris epithelial cells as a model of differentiation control. Differentiation, 27:1-12

Yamada, T., D.H. Reese, and D.S. McDevitt (1973) Transformation of iris into lens in vitro and its dependency on the neural retina. Differentiation, 1:65-82.

Zalokar, M. (1944) Contributions a l'etude de la regeneration du cristallin chez le Triton. Rev. Suisse, Zool, 51:444-521. 